\title{
Use and Abuse of Clinical Chemistry in Surgery
}

\author{
A. M. BOLD,* M.A., B.M., B.CH. ; B. CORRIN, $\dagger$ M.D.
}

Brit. med. F., 1965, 2, 1051-1052

The work of clinical chemistry laboratories is increasing inexorably. Whitby (1963) showed that in four hospital laboratories the work load doubled approximately every five years. Our laboratory has doubled its output in three years. Though a portion of this increase is due to the introduction of new tests, most is caused by more requests for longestablished tests. One result of this is that the more complicated tests and the introduction of new tests are delayed. Harassed laboratory staff often suspect that much of their work is unnecessary. We have attempted to discover if this suspicion is justified, and to find out how results of laboratory tests are used.

\section{Methods}

All requests for chemical tests on surgical patients from 8 August to 7 November 1964 were recorded.

A randomly selected proportion (every tenth request for electrolytes and urea, every third request for all other tests) were followed up by asking the senior registrar of the surgical firm concerned the following questions: (1) Why was the test done ? (2) Was the result considered abnormal ? (3) What action was taken as a result of the test ? (4) Would you prefer any alternative or additional chemical test not at present available? (5) Any other comments ?

The senior registrars approached were most co-operative, and we thank them for their help and patience. They were generally helpful in their comments and were prepared to point out all investigations they thought unnecessary. From the answers to our questions the tests were classified in the following categories (modified from Eastham and Pollard, 1964): (1) Diagnostic-making a firm diagnosis not possible on other grounds. (2) Supporting the clinical diagnosis. (3) Nonspecific. (4) Useful negative. (5) Progress. (6) Monitoring of treatment. (7) Unnecessary.

\section{Results}

Most of the results are shown in the Table.

The clinical details on the request cards sent to the laboratories were compared with the reason for the investigation given by the senior registrar. Twelve per cent. of all request cards carried no clinical details whatever. A further $11 \%$ had details which were irrelevant or inadequate. - Assistant Lecturer in Chemical Pathology, St. Thomas's Hospital and
Nedical School, London.
t Lecturer in Pathology, St. Thomas's Hospital and Medical School,
London.
The normal ranges for the estimations were well known by the surgeons, confirming our impression that, except for new or rare tests, report forms do not need abnormality to be underlined.

Only two new tests were requested: plasma (or urine) osmolarity, and a means of determining the source of a raised alkaline phosphatase. In general it was clear that the surgeons expected the laboratory to take the initiative for changes or additions to tests.

\section{Discussion}

In our hospital most tests are initiated by housemen. Overall, $11 \%$ of tests requested were considered unnecessary by the senior registrar of the firm concerned. Because of the design of the survey, this is a minimum rather than maximum estimate, though the surgeon's co-operation leads us to believe it is reliable. The unnecessary $11 \%$ is not a large proportion, but it does suggest that supervision of investigations could be stricter; alternatively it may be regarded as part of the price of training junior doctors. Although not shown in the Table, it was also clear that some investigations of a " portmanteau" nature-for example, electrolytes and urea, liver-function tests, calcium, phosphorus, and alkaline phosphatase-were requested somewhat indiscriminately, only one of the batch being required.

In spite of repeated exhortation from the laboratory, nearly a quarter of all request cards carried irrelevant, inadequate, or no clinical details. We sympathize with housemen who are already burdened with very long hours, but the absence of clinical details does make it impossible for the chemical pathologist to decide if any tests need checking or if additional tests should be performed, thus possibly saving much time. It also gives laboratory staff the impression that much of their work is unnecessary, an impression which this survey shows is largely erroneous.

Several other conclusions are suggested by the data in the . Table. Estimation of urine and faecal electrolytes is a valuable guide to post-operative intravenous fluid replacement, and, although more troublesome for ward and laboratory staff, it should replace or supplement plasma electrolyte estimations. Plasma protein estimations, however, appear to be of less value ; over $25 \%$ were considered to give non-specific information, and where clear indications are absent the helpful information likely to be gained from this test is small.

Of the tests $44 \%$ were considered to provide "useful negative" information, although the degree of usefulness is variable. Nearly half the tests in this category were baseline screening tests (pre-operative blood urea and electrolytes and

\begin{tabular}{|c|c|c|c|c|c|c|c|c|}
\hline Test & $\begin{array}{l}\text { Total } \\
\text { No. }\end{array}$ & Diagnostic & $\begin{array}{c}\text { Supporting } \\
\text { Clinical } \\
\text { Diagnosis }\end{array}$ & Non-specific & $\begin{array}{c}\text { Useful } \\
\text { Negative }\end{array}$ & Progress & $\begin{array}{c}\text { Monitoring } \\
\text { of } \\
\text { Treatment }\end{array}$ & Unnecessary \\
\hline $\begin{array}{l}\text { Blood electrolytes and urea } \\
\text { Urine and faecal electrolytes } \\
\text { Liver-function tests } \ldots\end{array}$ & $\begin{array}{l}93 \\
6 \\
61 \\
25\end{array}$ & $\begin{array}{l}0 \\
0 \\
0 \\
0\end{array}$ & $\begin{array}{r}2 \\
0 \\
16 \\
0\end{array}$ & $\begin{array}{l}1 \\
0 \\
9 \\
7\end{array}$ & $\begin{array}{r}25 \\
0 \\
21 \\
13\end{array}$ & $\begin{array}{r}36 \\
1 \\
7 \\
2\end{array}$ & $\begin{array}{r}13 \\
5 \\
0 \\
0\end{array}$ & $\begin{array}{r}16 \\
0 \\
8 \\
3\end{array}$ \\
\hline $\begin{array}{l}\text { phatase, urine calcium } \\
\text { Blood glucose, glucose tolerance test } \\
\text { Others } \\
\end{array}$ & $\begin{array}{l}73 \\
22 \\
64 \\
\end{array}$ & $\begin{array}{l}7 \\
3 \\
0\end{array}$ & $\begin{array}{l}5 \\
3 \\
8\end{array}$ & $\begin{array}{l}0 \\
0 \\
2\end{array}$ & $\begin{array}{r}44 \\
4 \\
43 \\
\end{array}$ & $\begin{array}{l}7 \\
2 \\
6\end{array}$ & $\begin{array}{r}5 \\
10 \\
0\end{array}$ & $\begin{array}{l}5 \\
0 \\
5\end{array}$ \\
\hline All tests & 344 & $10(3 \%)$ & $34(10 \%)$ & $19(5 \%)$ & $150(44 \%)$ & $61(18 \%)$ & $33(10 \%)$ & $37(11 \%)$ \\
\hline
\end{tabular}


tests for metabolic abnormalities in patients with renal calculi). Such a high proportion of screening tests, even in surgical patients, suggests a trend which is a big factor in the rising work load of clinical chemistry laboratories.

In $13 \%$ of all tests (categories 1 and 6 ) the management of the patient is largely or solely influenced by the result of the chemical tests. This stresses the need to maintain a high standard of care and accuracy in the laboratory, a searching problem when large numbers of samples are handled daily.

We are at the threshold of an era when multichannel analysers could make wide chemical screening of large numbers of patients relatively painless to the laboratory staff. However, until such a dream becomes reality, some restriction of investigations is unavoidable if really essential investigations are to be performed promptly and efficiently.

\section{Summary}

The work load of clinical chemistry laboratories is increasing rapidly. To discover how many chemical tests are really necessary, a three-month survey of tests on surgical patients has been carried out.

The information supplied by the tests was classified as follows : $3 \%$ provided diagnostic information ; $10 \%$ confirmed a clinical diagnosis; $18 \%$ helped to assess progress; $10 \%$ monitored treatment; $44 \%$ gave useful negative information; and $11 \%$ of the tests were considered unnecessary. Twentythree per cent. of request forms had irrelevant or no clinical details, and this is thought to explain why laboratory staff suspected that the proportion of unnecessary tests would be much higher than $11 \%$.

We are grateful to Professor F. T. G. Prunty and Dr. R. R. $\mathrm{McSwiney}$ for their advice, and to the Senior Surgical Registrars of St. Thomas's Hospital for their helpful co-operation.
A short conference on depressive illness in general practice was held at the Royal Festival Hall, London, on 14 October. It was attended by about 150 general practitioners from many parts of Great Britain. Organized by Dr. E. Beresford Davies (Cambridge), it was made possible by the generosity of Allen and Hanburys Ltd.

\section{Clinical Presentation}

During the morning session Professor W. J. H. Butterfield (London) took the chair. The opening speaker was Dr. C. A. H WATTS, a general practitioner of Leicester, who stressed the importance of the subject to the family doctor. He suggested that, whereas depressive disorders were seen every year in from 12 to 16 persons per 1,000 of the population who visited their doctors, something like 130 to 150 per 1,000 persons suffered from depression at home without seeking medical advice. While most of these patients had a minor disorder, a few were in urgent need of medical help. He went on to point out how endogenous depression could be disguised as an anxiety state or organic disease, or present as anti-social behaviour. He suggested it could also be grafted on to a physical illness, and then the latter was wrongly blamed for any deterioration. The obvious psychotic type of depression accounted for only about $5 \%$ of the total of cases seen in general practice.

Dr. JAMrs Flind (London) talked about the recognition of depression. He defined the endogenous type as a biochemical disorder in genetically predisposed individuals. It was twice as common in women as in men. $\mathrm{He}$ listed the various symptoms of the disease. The general practitioner had certain advantages over the consultant. Knowing his patients, he could readily detect any deviation from the norm, and he could easily get a history of the illness from relatives. Dr. Flind said that every effort should be made to prevent the patient from making important decisions while ill, and he underlined the urgency of assessing suicidal feelings in patients, a procedure which if properly performed always did good and never harm. $\mathrm{He}$ felt that many mild depressions could be treated by family doctors. Patients who were retarded, agitated, or self-reproachful, and persons with the delusion that they had cancer were best passed on to the consultant. $\mathrm{Re}$ active depression, he felt, was quite different. The patient was usually an inadequate personality, often with an insoluble problem. Both electric convulsion therapy and psychotherapy gave poor results, but in possibly $25 \%$ of cases the monoamine oxidase inh:bitors gave dramatic improvement.

\section{Use of Drugs}

Dr. P. J. Dally (London) completed the morning session by describing the place of drugs in depression. He suggested that imipramine (Tofranil) was the drug of choice in the mild endogenous depression, but the monoamine oxidase inhibitors were more effective in atypical depressions. These occurred in the person who tended to be anxious and phobic, who blamed others and was full of se'f-pity, or in the person with inferiority feelings who was often overconscientious and carried on in spite of symptoms. In cases showing extreme exhaustion tranylcypromine (Parnate) was of ten effective. Chlordiazepoxide (Librium) and meprob mate were useful adjuncts. The lifelong sufferer was not likely to be helped by any drug. Desipramine (Pertofran) was not as effective as imipramine, and when there was agitation he preferred to use amitriptyline and a phenothiazine drug. Severe cases were best treated by electric convulsion therapy, which was still the most effective anti-depressive agent. Imipramine could be used concurrently and had reduced the average number of shocks from nine to four. Drugs

\section{REFBRENCES}

lard, B. R. (1964).

A Laboratory Guide to Wancet, 2,1239 . alleviated the symptoms but did not cure the disense, and they had to be given until a natural remission set in ; a few patients might need drugs continuously for the rest of their lives. In a small minority of cases there was a place for using both imipramine and a monoamine oxidase inhibitor.

\section{Biochemical Factors}

The afternoon session was chaired by Dr. E. Beresford Davies, and Professor ErIR JACOBSEN (Copenhagen) opened with a summary of the biochemical background of depressive illness. The sudden onset and abatement which occurred in certain cases had convinced him this was a metabolic disease, and he felt that it was tied up with the function of noradrenaline, which was found in quantity round the basal ganglia and certain other parts of the brain. It had long been known that amphetamine uplifted the mood and did this by increasing noradrenaline activity. On the other hand, this activity could be reduced by reserpine, which could produce a depression indistinguishable from endogenous depression. Reserpine caused hypoactivity in experimental animals, and this could be prevented by giving a monoamine oxidase inhibitor drug at the same time. It seemed as if the latter prevented the lowering of noradrenaline levels. This offered an explanation of how these drugs helped some cases of mental depression. It was not so easy to explain how the imipramine group of drugs worked, but their function was quite different from the monoamine oxidase inhibitor group. It was even more difficult to explain the action of electric convulsion therapy.

\section{Management}

Dr. Seymour SPEncer (Oxford) followed on by describing how he felt the general practitioner should manage such cases in general 